\title{
A Simplified Method of Improving the Power Quality in Power Electronic Circuits using a Single Pair of IGBTs
}

\author{
Dr. Dakka Obulesu ${ }^{1}$, Mr. Rajashekher Koyyeda ${ }^{2}$, Dr. T.C.Manjunath ${ }^{3}$ \\ ${ }^{1}$ Assoc. Professor, CVR College of Engineering/ EEE Department, Hyderabad, India \\ Email : dakkaobulesh@gmail.com \\ ${ }^{2}$ Research Scholar (Part-Time), USN : 5VX17PES90, VTU RRC, Belagavi, Karnataka, India \\ Email: rajashekher.koyyeda@gmail.com \\ ${ }^{3}$ Prof. \& HOD, Dayananda sagar College of Engineering/ECE Department, Bangalore, Karnataka, India \\ Email : dr.manjunath.phd@ieee.org
}

\begin{abstract}
This paper presents a method to reduce harmonic components in voltage-sourced circuits utilizing IGBT switches and diodes using the PWM technique and also presents a technique to improve the power quality, using a single pair of IGBTs (level-1 or stage-1). This model was developed in Simulink using the designed circuitry, which can be used for improving the power quality. The simulation results are obtained by performing the simulations in the MATLABSimulink environment.The simulation results demonstrate the efficacy of the method developed for harmonic suppression in power electronics-based systems, which can greatly improve the power quality. The work can also be extended to a 2-level and a 3-level inverter for an improvised versions for future works.
\end{abstract}

Index Terms: Elimination, Breakers, Current, Voltage, Control, Simulation, Total Harmonic Deduction, Power Semiconductor Devices, Suppression, Power Quality, Harmonics, Distortion, Level, PWM, IGBT.

\section{INTRODUCTION}

The control of any device or equipment using electronic means in today's digital world finds many applications, which necessitates improvement in power quality. This world of innovations relies deeply on the seamless and continued access to electrical force or energy. Today's world is truly empowered to work at its busy pace by the availability of power commercially. Our homes and workplaces have seen the deep penetration of modern innovations and with the rise in electronic trade and commerce, the manner in which we interface with the world is constantly changing. A fundamental element in a modern and inclusively advancing nation is electric vitality. The proper quality of force, energy, or power can guarantee the ideal use of electric power. Since the power usage is relative, unwavering supply quality with flexibility of procedure is quite important [1-10].

In general, power is different from other commodities-it is created far away from where it will be used, it is transferred to the framework with the yield of many different generators, and it finally reaches the place where it is to be used through transformers in kilometers through overhead and conceivably underground cables. In privatized, commercial electrical businesses, various associations or companies own, supervise, and maintain the system resources. It is quite difficult to assure the quality and nature of the power that is transferred at the place and purpose of utilization.. Moreover, substandard power can neither be taken back from the store network nor rejected by the client or the end-user [11-20].

As mentioned, electrical power is a key element for development in any nation. Without electricity, the whole world will plunge into darkness, with the country's economy falling drastically - after all, every working device requires electricity. The world, therefore, should grateful to Thomas Alva Edison and Benjamin Franklin, Who discovered this great wonder, a thing of great importance today [21-30].

Harmonic spikes have various undesirable consequences for an appropriation framework of electrical distribution networks. They are of two types: short-term effects and long-term effects. Short-term effects are generally easily recognized, identified by over-the-top voltage mutilation. On the other hand, expanded resistive loss or voltage stress can normally identify long-term (also long-haul) effects, which frequently go undetected . Likewise, the consonant streams created by non-straight loads can associate destructively with a wide variety of electrical power equipment, mostly capacitors, transformers, engines, and generators, causing additional, overheating, loss and overburdening [31-40].

The development of harmonic currents causes interference in telephone cables and lines. Standards to depict a practical structure for harmonic surge control have been created to offset the adverse impacts of harmonic surges on power quality. The goal is to ensure consistent state harmonic limits that are considered acceptable by both electric utilities and their clients [41-50].

Distortion of harmonics within a power or force appropriation systems can be suppressed by implementing two methodologies: latent/passive and dynamic/passive and dynamic/active fueling. The passive type of sifting/filter by far remains the easiest and popular solution to address the problem of mutation encountered in harmonics. Since the use of detached components - which, over the years, have created an abnormal state of modernity - does not react precisely to the progression of electrical energy transmission frameworks, they have been modified to allow the 
sidestepping or even by passing of certain consonant frequencies.. [1-25].

Harmonics are voltage $(v)$ and current $(i)$ frequency components that are embedded at the crest level of the normal sine $v$ and $i$. The symphonious distortion in the waveform is mostly, because of significant increases of nonstraight loads and because of innovative progresses, e.g., the use of force electronics circuits and gadgets, in AC/DC transmission connections, or burdens in the control of force frameworks using power electronics or microchip controllers. Harmonic sources are categorized into three types of loads: household load, industry load, and controlling device [25-50].

Present-day electronic gadgets, served by power circulation circuits, possess some level of symphonious frequencies. Although the surge $\mathrm{v}$ and $\mathrm{i}$ do not generally create problems, the more pronounced electrical power or energy drawn by the advanced gadgets or other non-straight loads, the more pronounced is the voltage mutilation level. Harmonic generation is related to a number of complications, such as malfunctioning of the equipment; breakers tripping suddenly; lights turning on and off suddenly; large neutral currents; heating up of conductors in the phase, loads, and transformers; UPS and transformers failing suddenly; low power factor; voltage and current surges; and depletion of system's capacity [1-50].

Hence, the question now is how to prevent harmonics. To reduce the overall harmonic content in a device, circuit, equipment, or a part of the network. One efficient method is to select a device and follow a good installation practice. If for some reason the issues cannot be detected by these elementary measures, then two fundamental steps can be taken to strengthen the distribution framework to endure voltage or current surges or introducing a gadget to mitigate or eliminate the harmonics. There are numerous methods to lower voltage or currents surges; they can range from makeshift ones to even costly and elaborate ones. Some examples include incorporating latent symphonious channels, transformers that can confine or moderate consonants, harmonics suppression networks, and dynamic channel filtering mechanisms.

The harmonic effect in a system's voltage or current is always determined in terms of the total harmonic distortion (THD) factor and high- and low-level harmonic contents. Ideally, any industry application requires the load voltage or current to be free of harmonics or at the least be $<5 \%$ of the harmonics. Most studies have shown that the THD can be lessened by a number of methodologies. There are a number of structure arrangements that can be used to resolve or reduce the impact of supply quality issues, and it is an exceptionally dynamic area of development and improvement. In such a scenario, it is advisable for clients to know about the scope of arrangements available as well as the relative merits and costs. Some important techniques used to minimize sounds/surges in voltage or current are filters that are either passive or active in nature, separation transformers,surge-reducing transformers, surge-suppression systems, and so on.
For this study, a large number of research papers were collected from various sources, studied at length, and a brief review was carried out. In-depth reviews were performed for power-quality improvement on active filters, active power filters, and active harmonic filters by Singh B., Al-Haddak, Chandra A., El-Habrouk M., Darwish M.K., Mehta P., and Akagi $H$. These review papers prove sufficient for first-time reviewers to understand the basic concepts of filter design, its deployment, and its further use. The principle of generation of signals for inverters and converters, which could be used in power systems for harmonic eradication, has been explained in details by D. G. Lipot A. A new concept of selective harmonic elimination scheme (SHES) for a three-phase voltage source inverter (VSI) was presented by Karthikeyan et al. based on concepts of the generation of opposite harmonic injection using the software package MATLAB.

In most of the works performed by various authors or researchers discussed in the previous paragraphs [1-50], there were certain drawbacks, disadvantages, or failures, such as they developed the algorithms only for linear loads, but higher harmonics could not be eliminated and the control algorithms were not efficient, only two to three stages of designs were used, noise was one of the important factors that could not be eliminated, the performance indices were low, very few worked on nonlinear loads, that too with respect to inductive and capacitive loadings, and so on.

In this paper,will try to address some will try to address of the above-mentioned drawbacks [1-50], and the effects of harmonics on the various types of devices will be studied in brief, a thorough analysis will be made, and new algorithms will be developed to suppress the harmonics, which will be verified through effective simulation results in the MATLAB-Simulink environment, along with the development of some hardware implementation to substantiate the research problem undertaken.

One typical issue in electrical,electronics,mechatronic, instrumentation, and computer-based systems has been maintaining the THD at below 5\% level. When power sources are introduced into a circuit, it draws bended waveforms that contain some unwanted waveforms, which occurs due to the presence of direct and indirect loads. These sounds can impede the working of other electronic frameworks.

Consequently,it is important to quanity the aggregate impact of such sounds. Complete harmonic distortion provides data about the symphonious substance in a sign with respect to the key segment. Harmonic distortion levels in power systems are commonly measured as THD it can be defined as the ratio of total harmonics to the value at fundamental frequency [15].

It is mathematically represented as

$$
T H D=\frac{\sqrt{V_{2}^{2}+V_{3}^{2}+\ldots \ldots \ldots \ldots . .+V_{n}^{2}}}{V_{1}},
$$

where $V_{n}$ is the RMS voltage of the $n^{\text {th }}$ harmonic and $n=1$ is the fundamental frequency [1-25]. 
TABLE I.

FORMULAS FOR COMPUTING THE HARMONIC PARAMETERS

\begin{tabular}{|l|l|l|}
\hline Harmonic order & $n=f_{\mathrm{n}} / f_{1}=\mathrm{G} X_{C} / X_{L}$ & $\begin{array}{l}f_{1}=\text { fundamental } \\
\text { frequency }\end{array}$ \\
\hline Quality factor & $Q=n X_{\mathrm{L}} / R=X_{\mathrm{C}} /(n R)$ & $\begin{array}{l}\omega=2 \pi f_{1}=\text { angular } \\
\text { frequency }\end{array}$ \\
\hline Bandwidth & $B=f_{\mathrm{n}} / Q$ & $f_{\mathrm{n}}=$ tuning frequency \\
\hline Reactive power at $f_{1}$ & $Q_{\mathrm{C}}=\left(V^{2} / X_{\mathrm{C}}\right) \cdot n^{2} /\left(n^{2}-1\right)$ & $\begin{array}{l}n=\text { harmonic order }= \\
\left(\mathrm{f}_{\mathrm{n}} / f_{1}\right)\end{array}$ \\
\hline $\begin{array}{l}\text { Active power } \\
\text { at } f_{1}(\text { losses })\end{array}$ & $P \approx\left(Q_{\mathrm{C}} / Q\right) \cdot n /\left(n^{2}-1\right)$ & $\begin{array}{l}V=\text { nominal line-line } \\
\text { voltage }\end{array}$ \\
\hline & & $\begin{array}{l}X_{\mathrm{L}}=\text { inductor reactance } \\
\text { at } \\
\text { fundamental frequency } \\
=L \omega\end{array}$ \\
\hline & where & $\begin{array}{l}X_{\mathrm{C}}=\text { capacitor } \\
\text { reactance at } \\
\text { fundamental frequency } \\
=1 /(C \omega)\end{array}$ \\
\hline
\end{tabular}

It is quite important to discuss the consequences of harmonics in power electrical devices, with one major effect of power system harmonics being that the current in a system which increases. This happens particularly for the third harmonic, generating a sharp increase in the zero sequence current and consequently increasing the current in the neutral conductor. This fact needs to be taken into consideration when designing an electric system that can serve nonlinear loads. Along with the increased line current, different parts of the electrical equipment can undergo damage due to the effects of harmonics on power systems. Harmonics have been experienced by electrical systems since a long time, starting from when the first AC generator went online more than a century back. Harmonics, which is very important in supplying smooth power to devices, were however very minor and had no detrimental effects back then; however, currently, with the rapid development of industrialization, it has to be given due consideration [26$50]$.

This study has been sectioned as follows. A background introduction with respect to the work done is presented in the Introduction section 1. Review of the single-stage inverter is presented in section 2. Development of the Simulink model is presented in section 3. Selection of the simulation parameters is presented in section 4. Running of the developed Simulink models, i.e., the process of simulation, as well as observation of the results is presented in section 5. In section 6, a discussion on the simulated results is presented, along with comments on the reduction of THD in the work considered. Conclusions are presented in section 7 , followed by the acknowledgments in section 8 and a brief list of references used in the research paper in the reference section models.

\section{REVIEW OF The Single-STAGe INVERTER}

In this section, single-phase circuits, i.e., inverters, are designed in such a way that maximum harmonic contents can be reduced using single-stage, double-stage, or triple- stage half-bridge-full-bridge inverters so that the harmonic contents are reduced when the load is switched on and off. However, as per the context, we have used only a singlephase inverter, i.e., one stage only.

IGBTs and diode blocks are used in the construction of multistage models. IGBTs are very powerful switching devices that can be used for full harmonic suppression to obtain a smoothened output free of harmonics. After designing a proper filter and placing it at the output of the inverter, the harmonics-free waveforms can be observed. Finally, FFT analysis is carried out using the FFT commands and the "powergui" tools available in the MATLAB-Simulink window. The design is performed in one stage only, i.e., using a single pair of IGBTs.

IGBT and diodes are used to design the voltage source converter, which are controlled in the OL fashion using the discrete PWM generator. In this context, it is to be noted that the IGBT is a modified version of a gate turn-off (GTO) switch or a metal oxide silicon field effect transistor (MOSFET). In these devices, the forward voltages of the models are not considered as they do not have any role to play. The harmonic elimination system consists of only 1- $\phi$ models, i.e., a one is a half-bridge (single stage), and finally the performance criteria are evaluated for the single-phase case.

\section{DeVelopment OF The Simulink Model}

The Simulink model can be constructed using certain blocks available in the Simulink modeling library: thyristor bridges,DC sources, transformers, inductive loads, gain blocks,multiplexers,FWDs,scopes,scinks, output sources, comparators,pulse generators, and connectors Once the circuit is designed, all of the blocks have to be pulled from the Simulink library into the model and a file has to be developed. In addition, various toolboxes, such as the control system toolbox, the sim-power-systems toolbox, and signal processing toolboxes available in the Simulink, library are used. Scopes are connected at the outputs and inputs to observe the different waveforms. Note that each leg of an inverter consists of a pair of IGBTs.

Our design is used in parallel combination as it a wellknown fact that when harmonic filters are connected in parallel, they yield excellent harmonic reduction in the output voltage. In the Simulink model shown, the singlephase circuit uses the same DC voltage $\left(V_{\mathrm{dc}}=100 \mathrm{~V}\right)$, carrier frequency $(1 \mathrm{kHz})$, and modulation index $(m=0.9)$ for obtaining improvement in power quality. When developing the Simulink model, numerous parameters require to be set in the various blocks. In addition, to help detect voltage and currrent waveforms, scopes are connected at requisite points. 


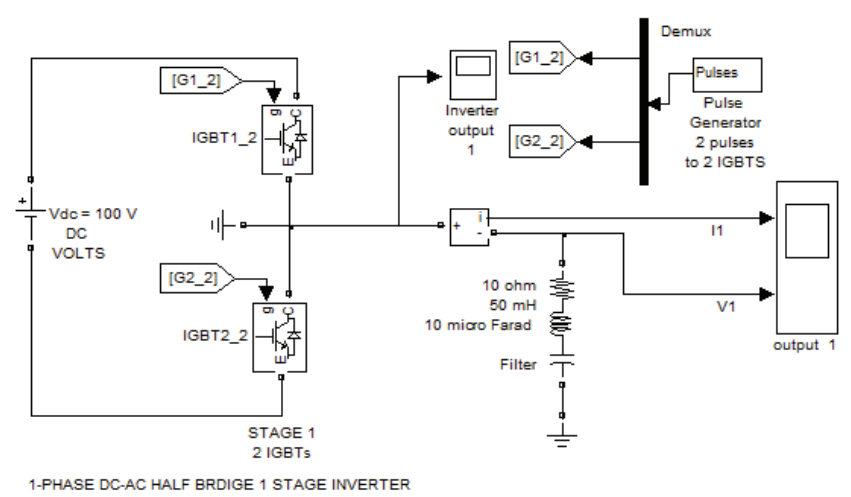

Figure 1. Simulink models for the one-stage harmonic reduction systems

The output signals are seen in the scope connected to stage-1, which shows that there is a drastic improvement in the harmonic-level suppression. An RLC filter stage is designed in such a way that its anti-harmonic signals are produced for the suppression of harmonic devices, which are produced due to the inverter actions, to obtain smooth output waveforms and to further improve the power quality. Outputs are observed for RL-, LC-, R-, and L-type filters also at the output of the load. In above Fig 1. The modeling design is performed in one stage only, viz., using a $1-\phi$, halfbridge inverter with one pair.

\section{Selection of the Simulation Parameters in SimulinK}

Before one can run the developed Simulink model, there are numerous parameters that need to be set in the different blocks used during its development; these parameters have been reproduced in the figures shown below. On selection of a desired block, it is double-clicked, following which the simulation parameters are entered and then saved.

\section{Simulation Process Developemnt}

After the Simulink model is run for the requisite simulation time, two waveforms are observed: one at the output of the inverter, which is affected by harmonic content, and the other at the output of the filter combined with the load, which is harmonic free. From the simulation results, it can be seen how the harmonics are removed to a great extent, as observed from the difference between before and after the incorporation of the harmonic filter. This shows the effectiveness of the method demonstrated in this section as to how to improve the power quality and obtain smoothened outputs at the receiving ends. Note that wherever switches come, the next immediate output will be the harmonics. Hence, this can be eliminated using multistage leg inverters; this will be further discussed in our future work. In the current research work however, only the preliminary stage, i.e., the one stage, is used for rectification of the harmonics generated as well as for improving the power quality.

\section{1- $\phi$, HALF Bridge InVERTER With ONE PAIR (With Simulink Diagram and ResUlts)}

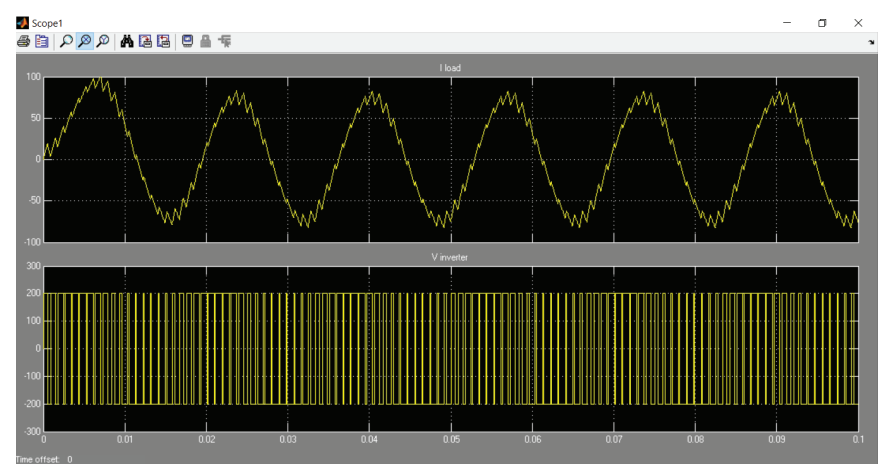

Figure 2. Simulink output display of the harmonic components waveform of the stage-1 inverter.

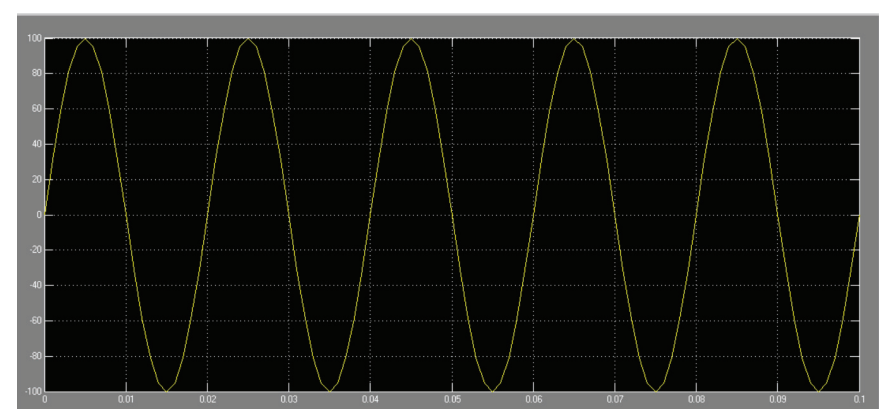

Figure 3. Simulink output display of the harmonic components waveform of the stage-1 inverter, after the output is filtered.

A 1- $\phi$, half-bridge inverter consists of only a pair of IGBTs in series, to which the inputs are given from the PWM generators (supplying pulses) and the $V_{\mathrm{dc}}$ voltage. In turn, the output of the 1- $\phi$ half-bridge is connected to an RLC filter bank, which suppresses the harmonic contents in the output supply voltage, as can be seen from scope 1 . Since there are two IGBTs in series in a line, the output of the pulse generator is multiplied and given to two devices.

Once the model is developed, the simulation is run for a specific period of time, which can be specified in the simulation time parameter section. The FFT analysis or the frequency spectrum can be demonstrated once the simulation is completed for the set specific simulation period. In the first case, the 1- $\phi$, single-stage half-bridge inverter generates a bipolar voltage $(-100 \mathrm{~V}$ or $+100 \mathrm{~V})$, and the harmonics occurs around the carrier frequency of $f_{\mathrm{c}}=1$ $\mathrm{kHz}$ with a maximum of $90 \%$ at $f_{\mathrm{c}}$. An FFT on the first-stage load output waveform is performed next, and it appears that the THD of the load current is around $10 \%$ for the halfbridge inverter.

Fig. 2 shows that before the introduction of the harmonic filter, as seen from the waveform, there were numerous harmonic contents $(3,5,7 \ldots)$. Fig. 3 shows the pulse width modulated scheme for controlling the harmonics. Once the harmonic filter is implemented, the Simulink output display of the harmonic components' waveform of the stage-1 inverter, after the output is filtered, is shown in Fig.3. The figure shows that the design is perfect as most of the 
harmonic contents are removed, the output is smoothened, and the power quality is improved tremendously, which can be proved by comparing the different parameters with respect to the IGBT designed circuit for the case considered.

TABLE II.

COMPARISON OF DIFFERENT PARAMETERS WITH RESPECT TO THE IGBT DESIGNED CIRCUIT FOR THE CASE CONSIDERED

\begin{tabular}{|l|l|}
\hline Type of harmonic elimination method & 3- $\phi$, -level inverter \\
\hline THD before harmonic suppression (load v) & $0.1515 \quad 15.2 \%$ \\
\hline THD after harmonic suppression (load $v)$ & $0.0175 \quad 1.75 \%$ \\
\hline THD before harmonic suppression (load $i)$ & $0.1468 \quad 14.68 \%$ \\
\hline THD after harmonic suppression (load $i)$ & $0.0123 \quad 1.23 \%$ \\
\hline Power factor (before) & 0.85 \\
\hline Power factor (after) & 0.9 \\
\hline
\end{tabular}

\section{Conclusions}

This paper presented a simplified method of improving the power quality in power electronic circuits using a single pair of IGBTs. Models, which were developed in the Simulink environment, were run, and the results obtained were observed. Using the total harmonic deduction formulae, the THD for the output waveforms for the current and voltage was calculated, and the results obtained were tabulated in the form of a THD reduction table. These quantitative results proved that the PWM scheme worked successfully because the THD, which had $15.2 \%$ harmonic contents before the introduction of the harmonic filter, saw a substantial reduction in its harmonic contents of load voltage down to $1.75 \%$ after the introduction of the harmonic filter. Similarly, once the proposed algorithm was implemented, the THD of $14.68 \%$ harmonic contents of the load current before the introduction of the filter substantially reduced to $1.23 \%$ after the introduction of the filter. The results obtained from the MATLAB output THD waveform evidence this fact. The net power factor too improved from 0.75 to 0.8 .

\section{REFERENCES}

[1] Zainal Salam, Tan Perng Cheng and Awang Jusoh, "Harmonics mitigation using active power filter : A technical review", Elektrika, Vol. 8, No. 2, pp. 17-26, 2006.

[2] Fanghua Zhang \& Yangguang, "Selective harmonic elimination PWM control scheme on a $3-\phi 4-$ leg voltage source inverter", IEEE Transaction on Power electronics, Vol. 24, No. 7, pp. 1682-1689, Jul. 2009.

[3] Mahesh A. Patel, Ankit R. Patel, Dhaval R. Vyas \& Ketul M. Patel, "Use of PWM techniques for power quality improvement", International Journal of Recent Trends in Engineering, Vol. 1, No. 4, pp. 99-102, May 2009.

[4] Ming-Yin Chan, Ken KF Lee \& Michael WK Fung, "A case study survey of harmonic currents generated from a computer center in an office building", Architecture Science Review, Vol. 50, No. 3, pp. 274-280, 2007.

[5] G.N.C. Fergusson, "Power quality improvement in a harmonic environment", International Electrical Testing Association (NETA) Annual Technical Conference - A reprint version, Mar. 1997.

[6] Thomas S. Key \& Jih-Sheng Lai, "Costs and benefits of harmonic current reduction for switch mode power supply in commercial office building", IEEE Trans. on Industry Applications, Vol. 32, No. 5, Sep.-Oct. 1996.

[7] V. Suresh Kumar, Ahmed F. Zobaa, R. Dinesh Kannan, \& K. Kalaiselvi, "Power Quality and Stability Improvement in Wind Power System using STATCOM", International Conference and Exhibition on Green Energy and Sustainability for Aride regions \& Mediterranean Countries, 2009.

[8] Alexander Kusko \& Mart C. Thomson, "Power quality in electrical systems", Tata Mc. Graw Hill., New Delhi, 2010.

[9] Gregory N.C. Ferguson "The cost and benefits of harmonic current reduction in low voltage distribution systems", Int. Jr. of Power Quality, Vol. 3, No. 5, pp. 45-51, May 2013.

[10] Jonathan K. Piel \& Daniel J. Carnovale, "Economic and electrical benefits of harmonic reduction methods in commercial facilities", Proc. Cutler Hammer, USA, Jul. 2004.

[11] M. Aredes, J. Hafner, and K. Heumann, "3-phase four-wire shunt active filter control strategies," IEEE Trans. Power Electron., Vol. 12, No. 2, pp. 311-318, Mar. 1997.

[12] C. J. Zhan, A. Arulampalam, and N. Jenkins, "4-wire dynamic voltage restorer based on a 3-dimensional voltage space vector PWM algorithm," IEEE. Trans. Power Electron., Vol. 18, No. 4, pp. 1093-1102, Jul. 2003.

[13] N.Y. Dai, M.-C.Wong, andY.-D. Han, “A FPGA-based generalized pulse width modulator for 3-leg center-split and 4-leg voltage source inverter," IEEE Trans. Power Electron., Vol. 23, No. 3, pp. 1472-1484, May 2008.

[14] H.L. Jou, J.C. Wu, K.D. Wu, W.J. Chiang, and Y.H. Chen, "Analysis of zig-zag transformer applying in the three-phase four-wire distribution power system," IEEE Trans. Power Del., Vol. 20, No. 2, pp. 1168-1173, Apr. 2005.

[15] P. Sanchis, A. Ursua, E. Gubia, J. Lopez, and L. Marroyo, "Control of three-phase stand-alone photovoltaic systems with unbalanced loads," Proc. IEEE ISIE, pp. 633-638, 2005.

[16] G. Kamath, N. Mohan, and V.D. Albertson, "Hardware implementation of a novel, reduced rating active filter for 3phase, 4-wire loads," Proc. IEEE APEC, pp. 984-989, 1995.

[17] S. Choi and M. Jang, "Analysis and control of a 1- $\phi$ inverter zigzag-transformer hybrid neutral-current suppressor in 3- $\phi 4-$ wire systems," IEEE Trans. Ind. Electron., Vol. 54, No. 4, pp. 2201-2208, Aug. 2007.

[18] S. Kim and P.N. Enjeti, "A new hybrid active power filter (APF) topology," IEEE Trans. Power Electron., Vol. 17, No. 1, pp. 48-54, Jan. 2002.

[19] G. Casaravilla, G. Eirea, G. Barbat, J. Inda, and F. Chiaramello, "Selective active filtering for 4-wire loads: Control and balance of split capacitor voltages," Proc. IEEE PESC, pp. 4636-4642, 2008.

[20] N.Y. Dai, M.C. Wong, and Y.D. Han, "Application of a 3level NPC inverter as a 3-phase 4-wire power quality compensator by generalized 3D SVM," IEEE Trans. Power Electron., Vol. 21, No. 2, pp. 440-449, Mar. 2006.

[21] IEEE 100, The Authoritative Dictionary of IEEE Standard Terms, 7th edition, pp. 234, 2000.

[22] S.Khalid \& Bharti Dwivedi, "Power quality issues, problems, standards \& their effects in industry with corrective means", Int. Journal of Advances in Engg. \& Tech., IJAET, ISSN: 2231-1963, Vol. 1, Issue 2, pp.1-11, May 2011.

[23] Rajesh Maharudra Patil, Dr. M.S. Nagaraj, Dr. P.S.Venkataramu, "A review of the effect of harmonics due to switching devices in the field of power electronics \& its applications", Int. Jr. of Emerging Tech. \& Research (IJETR), ISSN (E) : 23475900 ISSN (P) : 23476079, IF : 0.997, Vol. 2, No. 2, Mar-Apr. 2015, pp. 44-50

[24] http://www.ijetr.org/index.php?p=pi\&volume=V2\&issue=I2 
[25] Narain G. Hingorani and Laszlo Gyugyi, "Understanding FACTS : Concepts and technology of flexible AC transmission systems", Wiley-IEEE Press, 452 pages, 1999.

[26] Suvas Vora, Dipak Bhatt, "A comprehensive review of harmonics effects on electrical power quality", Int. Journal of Engg. Development \& Research, Paper id IJEDR1303003, ISSN: 2321-9939, pp. 15-21, 2013.

[27] Chandrasekar, T., Justus Rabi and A. Kannan, "Harmonics reduction in front end rectifier of uninterruptible power supplies with active current injection", American Journal of Applied Sciences - Science Publication., Vol. 11, No. 4, pp. 564-569, ISSN: 1546-9239, pp. 564-569, doi:10.3844/ajassp.2014.564.569, 2014.

[28] Harish Kumar S., Vengatesh V., Bhuvaneswaran E., "Power quality management in commercial buildings", Int. Journal for Research \& Development in Engg. (IJRDE), ISSN: 22790500, Special Issue, pp. 157-165, 2014.

[29] Alireza Hoseinpour and Reza Ghazi, "Modified PWM technique for harmonic reduction", Int. Scholarly Research Network ISRN Electronics, Vol. 2012, Article ID 917897, 8 pages, doi:10.5402/2012/917897.

[30] K.L. Lian, Brian K. Perkins, and P.W. Lehn, "Harmonic analysis of a $3 \phi$ diode bridge rectifier based on sampled data", IEEE Transactions on Power Delivery, Vol. 23, No. 2, pp. 1088-1096, Apr. 2008.

[31] M.H. Shwehdi, F.S. AL-Ismail, "Investigating University Personnel Computers (PC) Produced Harmonics Effect on line Currents", Int. Conf. on Renewable Energies \& Power Quality (ICREPQ'12), Santiago de Compostela (Spain), 28-30 Mar. 2012.

[32] Sagayaraj R., Thangavel S., "Implementation of intelligent control strategies on current ripple reduction and harmonic analysis at the converter side of the industrial inverters \& trade off analysis", Jour. of Theoretical \& Applied Info. Tech. (JATIT), ISSN: 1992-8645, Vol. 65 No. 2, pp. 344-351, Jul. 2014.

[33] Alham, M.H., Hassan M.A.M., El-Zahab, "Control of the shunt active power filter using artificial intelligence techniques", IEEE Int. Conf. on Control, Decision \& Info. Tech. (CoDIT), Hammamert, pp. 202-207, 2013.

[34] Sam Abdel-Rahman, Franz Stückler, Ken Siu, "PFC boost converter design guide, Infineon", Application notes.

[35] Satheeswaran K., Nepolean C., Vikash M., "Harmonic elimination using boost converter", International Journal of Scientific Engineering and Applied Science (IJSEAS), ISSN: 2395-3470, Vol. 1, Issue 9, Dec. 2015, pp. 431- 434.

[36] P. Suresh Kumar, S. Sridhar, T. Ravi Kumar, "Design \& simulation of boost converter for power factor correction and THD reduction", Int. Jr. of Scientific Engg. \& Tech. Res. IJSETR, ISSN 2319-8885 Vol. 3, Issue 42, pp. 8462-8466, Nov. 2014.

[37] Mohammad Junaid \& Bhim Singh "Analysis \& design of buck-boost converter for power quality improvement in high frequency on/off-line UPS system”, IEEE International Conference on Power Electronics, Drives and Energy Systems (PEDES), Mumbai, Print ISBN: 978-1-4799-6372-0, pp. 1-7, 16-19 Dec. 2014.
[38] K.S.V.Phani Kumar, S.Venkateshwarlu , "A Review on Power Quality in Grid Connected Renewable Energy System", CVR Journal of Science and Technology, Volume 5, pp.84-89, December 2013.

[39] G.Sree lakshmi, "Diode Clamped Multilevel Inverter Fed SPMSM", CVR Journal of Science and Technology ,Vol.13, pp. 56-60, December 2017.

[40] Singh B., Al-Haddak, Chandra A., "A review of active filters for power quality improvement", IEEE Transactions on Industry Electronics, Vol. 46, No. 5, pp. 960-971, 1999.

[41] El-Habrouk M., Darwish M.K., Mehta P., "Active power filters : A review", Electric Power Applications, IEE Proc., Vol.147, Issue 5, pp. 403-413, 2000.

[42] Akagi H., "Active harmonic filters", Proc. of the IEEE, Vol. 93, Issue 12, pp. 2128-2141, Dec. 2005

[43] Holmes D.G., Lipot A., "Pulse width modulation for power converters: Principles and practice", IEEE Press Series on Power Engineering, Wiley-IEEE Press, Edition 1, Oct. 2003.

[44] V. Karthikeyan, V.J. Vijayalakshmi, P. Jeyakumar, "Selective Harmonic Elimination (SHE) for 3-Phase Voltage Source Inverter (VSI)", American Journal of Electrical and Electronic Engineering, Science and Education Publishing, DOI:10.12691/ajeee-2-1-4.

[45] Ray R.N., Chatterjee \& Goswami S.K, "Reduction of voltage harmonic using optimization - based combined approach", Proc. on IET Power Electronics, Vol. 3, Issue 3, pp. 334 344, 2008.

[46] Mohamed S.A., Dahidah and Vassilios G. Agelidis, "Selective harmonic elimination PWM control for cascaded multilevel voltage source converters: A generalized formula" IEEE Trans on power electronics, Vol. 23, Issue 4, pp. 1620-1630, Jul. 2008.

[47] Wells, Jason R., Xin Geng, Chapman, Patrick L. \& Krein, Philip T. "Modulation based harmonic elimination" IEEE Transactions on Power Electronics, Vol. 22, Issue 1, 2007.

[48] G.Manohar,Dr.S.Venkateshwarlu "Performance Analysis of three level diode clamped Inverter fed Induction machine using Multicarrier PWM Techniques",CVR Journal of Science and Technology, Vol. 16,pp.59-65,June 2019.

[49] Hadji S. Touhami O. and C.J. Goodman, "Vector- optimized harmonic elimination for single phase pulse width modulation inverters / converters", IET Electrical Power Appl., Vol. 3, pp. 423-432, 2007.

[50] Agllidis V.G., Balouktsis A. \& Cosar C., "Multiple sets of solutions for harmonic elimination PWM bipolar waveforms: Analysis \& experimental verification", IEEE Trans. Power Electron., Vol. 22, No. 1, pp. 491-499. 2007. 